\title{
CHALLENGES AND OPPORTUNITIES IN PRACTICAL TRAINING - PERCEPTIONS OF CLINICAL EDUCATION
}

\author{
KADRi PILL ${ }^{1}$ AND EINIKe PiLli ${ }^{2}$ \\ ${ }^{1}$ Institute of Exercise Biology and Physiotherapy, University of Tartu, Tartu, Estonia \\ ${ }^{2}$ Lifelong Learning Center, University of Tartu, Tartu, Estonia
}

\begin{abstract}
The aim of the present study was to analyse students' perceptions of clinical education - what kind of learning opportunities they had and what kind of challenges they met. Eighty six different feedback forms were analysed, which were gathered from 28 third-year physiotherapy students after their final practical training was over. Answers to the questions were analysed by the method of content analysis and divided into categories. Students appreciated when they were treated as equals, their opinion was listened to and their preferences were taken into consideration. However, not everybody was satisfied with the relationship with supervisor. Respondents mentioned several aspects of the pedagogical skills of their supervisors. These were as follows: increasing students' independence, planning the learning process, asking questions, and giving feedback. Students were content with their training when they saw different patients who had varied diagnoses. They also liked when the placement was well-equipped and the emotional climate was friendly and positive. Sometimes students had feelings that they did not do anything educative. Sometimes students felt that the emotional climate was tense or they did not understand the rules.
\end{abstract}

Keywords: clinical education, importance of practical training, perception of physiotherapy students 


\section{INTRODUCTION}

Practical training, part of any holistic curriculum, gives the possibility to place theoretical knowledge, skills, attitudes and values into a real work environment. The most challenging aspect of practical training is how to organise it to be successful and meaningful for all parties. These two issues are crucial from the point of view of the learner, higher education institution, supervisor and clinical placement. The key element in organising and implementing the practical training process is preparation of all parties, which comprises expectations, common understanding of the goal and learning outcomes, and awareness of challenges and perceptions.

Practical training and supervision are core parts of physiotherapy programmes. During clinical experience, students learn to use, adapt and integrate the theoretical aspects of the profession [6]. Learning in a clinical environment does not simply occur by doing practical training. In clinical learning, the students enter into a difficult, complex, multidimensional and unknown world where social and cultural reality and rules might be different from university settings [16]. Practical training or clinical learning are synonyms for the term clinical education.

Clinical education is known as the tool of bridging the worlds of theory and practice, teaching real-world laboratory lessons that can only be learned through practice, introducing students to the peculiarities of the practice environment and the profession, as well as refining knowledge, psychomotor skills, and professional behaviours by managing patients with progressively more complex pathologies [7].

Kilminster et al. [9] define clinical education as a provision of guidance and feedback on personal, professional and educational development in the context of providing adequate patient care. This means clinical education is the key element for the development of the health care professionals and for providing quality service to the patients. However, it takes time to get used to and understand this reality. Learning in practice implies being able to function and interact with patients, supervisors, other physiotherapists, and fellow students [13].

In this context, it is crucial to have a clear understanding of the terms, definitions, and overall processes associated with practical training. If the idea of practical training is poorly understood, not all parties involved will be sufficiently prepared for training and several problems are likely to occur [14]. These problems, as pointed out by Corey et al. [2], can be categorized into four major problem groups: professional, consistent, intervention and trainingspecific problems. 
Professional problems are related to questions about educational preparation, awareness of individual differences and differences within varying sociocultural roles. Consistent problems are related to attitude to every-day work: confidentiality, ethics, openness, tolerance, professional behaviour and attitude. Intervention problems are related to working with patients: coping with clinical problems, dealing with patient cases and using clinical thinking. Training-specific problems are related to students' roles (self-awareness and integration into decision making), competences (balance between the task and skills), supervision (teaching methods used, problem solving capacity, and communication) and placement (qualitative contracts and facilities) [2].

Every practical training experience is unique. Despite that, there are still similarities found which are put together as a framework of the training experience. There are five developmental stages in an internship: anticipation, disillusionment, confrontation, competence, and culmination [15]. Anticipation is marked positive expectations, and anxiety due to unknown factors. During the disillusionment stage, student morale and task accomplishment drops. The enthusiasm and excitement that interns anticipated, and first experienced, has now diminished. Students' disappointment might be related to a supervisor or tasks and concerns about their own performance. In the confrontation stage, students address earlier disappointments and resolve the issues underlying earlier frustrations.

Overcoming these barriers helps to build confidence and independence. This may take place between a trainee and his/her clients, other physiotherapists and supervisors. Stage four is marked by high morale, a sense of purpose and accomplishment, high self-esteem and a clearer sense of one's capabilities. In the culmination stage, students' morale is typically based on their ability to provide closure with clients, co-workers and supervisors. Accomplishments decrease and trainees feel a wide range of emotions as they deal with ending the internship [4].

In clinical practice there is a wide range of tasks and stages of varying difficulty that the student will, in due time, be able to cope and deal. How quickly the trainee will be able to adapt and learn, will vary according to in what way work is organised - how much the student is involved in and supported by his/ her supervisor and/or other experienced physiotherapists [8].

Vagstøl and Skøien [16] found out how a positive learning climate is created by two dimensions: sense of trust and security, and balance of challenge and support. Students experience both trust and security when they witness the following as readily available: an open attitude, experience, and the presence of the supervisor. Students say that a clinical educator must be a good 
communicator, able to create personal interactions with the students, show enthusiasm and genuine interest, willing to listen to and understand the students ' perspectives, and must have the ability to see and meet students with respect. Students appreciate the clinical educators ' pedagogical ability and value someone who shows interest in their own learning process, and has an openness and willingness towards discussions and mutual development of knowledge and skills $[13,16]$. Another dimension was balance between challenge and support. Students appreciate a clinical educator who asks questions, waits to give the right answers, fosters independent thinking in students, and reflects and gives immediate mutual feedback. Students report that when the clinical educator inspires, believes and trusts in a student 's ability to manage a situation or task, the student tries to live up to that trust. Although, students want to have independent assignments, they do not want to be completely left on their own. Students strongly point out the importance of constructive feedback as well [6, 16]. In Skøien et al. [13] study, students pointed out other issues: having enough time for clinical work, for preparation, for patient meetings and for reflection. Clinical reasoning and reflection are essential parts of the development of professional practice [5].

It has been found that physical surroundings are also very important concerning learning in a clinical environment. The opportunity to use relevant equipment to create and carry out students' intentions in treatment and being watched in an open therapy room is influencing students actions', dialogues and reflections [13].

Some researchers have found that students emphasise the importance of fellow students. Peer learning and collaborative learning are terms often used in relation to students in practical training. It has been suggested that active support from a fellow student reduces the feelings of social isolation and communication barriers experienced by trainees in clinical placements, helping them to deal with the challenges and reducing the factors that have an impact on anticipation. In addition, peer learning facilitated understanding of mentorship and created a sense of readiness for professional practice $[1,11]$.

Despite that, it appears that effectiveness of the clinical training process still depends more on the supervisory relationship and less on the supervisory methods used $[3,9,10]$. Nevertheless, the need to develop guidelines for supervisors and advocate a need to re-assess methods used in clinical education is evident [9].

Learning in a clinical environment is extra challenging because patients are present and expect treatment. This raises the question of how to organise and develop both patient-centered and student-centered clinical education 
programmes [6]. Such a question highlights the importance to examine students' and supervisors' perceptions of clinical education in the context of student-centredness versus patient-centredness - the opportunities and challenges. The goal of the present study is to analyse students' perceptions of clinical education - what kind of learning opportunities they had and what kind of challenges they met.

\section{MATERIALS AND METHODS}

To understand better what students experience during their clinical practical training, we analysed 86 different feedback forms, which were gathered from 28 third-year physiotherapy students after their final practical training was over. Each student completed three different forms as they did their practical training in three different placements. This feedback was gathered during the three months of spring 2012. In total, students gave feedback to 23 different placements from all over Estonia. Most of the institutions were hospitals $(\mathrm{n}=13)$, some were rehabilitation centers $(n=4)$ or policlinics $(n=3)$, one was a kindergarten and two were schools for children with special needs.

Students were asked two questions. First, they were asked whether the environment of the practical training supported achieving the learning outcomes and how. The second question asked if and why they thought supervisors met their expectations. They responded in a written form, with their signatures below the writing.

Answers to the questions were analysed by the method of content analysis and divided into categories. In their replies, students touched a variety of issues. The majority of the respondents were satisfied and content with their experience of practical training.

\section{RESULTS}

\section{Relationship with the supervisor}

Personal relations between supervisors and students were mentioned quite often in the feedback. Students appreciated when they were treated as equals, their opinion was listened to and their preferences were taken into consideration. Flexibility in case of students' problems (e.g. illness of a child) was also mentioned.

Sometimes supervisors had no answers to the students' questions. However, they sent students to another person who knew the answers or they looked 
the answers up together. Supervisors encouraged students to think creatively, communicate openly and stay focused. Several respondents mentioned that suporvisors challenged them in a good way and that they had to work hard to achieve results.

However, not everybody was satisfied with the relationship with supervisor. Some of the students said that even as the supervisor had professional knowledge, she did not create a good learning environment. Another respondent felt that the supervisor's knowledge finished before the practical training was over.

One student expressed the expectation to have more guidance at the beginning of the process and another was sad because she did not get feedback and guidance during the process of therapies, even though it was written in the learning agreement. Sometimes students felt that they were left alone to deal with tasks that the supervisors did not like (e.g. working with children). Where there was only a little amount of supervision, the working relationship between student and supervisor was not created. Some other relationships were not formed easily, but in the end these worked out.

Some students were disturbed by the authoritarian attitudes of the supervisors. They felt that the relationship was in its best format when they did not express their opinion.

\section{Pedagogical skills of the supervisor}

Respondents mentioned several aspects of the pedagogical skills of their supervisors. These were as follows: increasing students' independence, planning the learning process, asking questions, and giving feedback.

\section{Increasing students' independence}

Supervisors were praised for not leaving students alone, but helping them with questions and problems and in the midst of difficult situations. They did therapy together with students first, gave enough time to get used to that, and then gave them increasingly more opportunity to plan therapy and do it by themselves. Some students appreciated that the supervisor gave enough independence and freedom, while at the same time giving enough feedback.

\section{Planning the learning process}

Students valued when supervisors planned practical training exercises and therapy together with them. This could take the form of planning the day, giving homework, suggesting additional reading, organising possibilities to meet 
patients with different diagnoses or use different therapies. Students also appreciated when supervisors gave them information about the placement and its rules.

\section{Teaching and asking questions}

Supervisors who explained their choices and activities helped students to learn and connect theory and practice. Questions helped students to remember what they had learned about the practical situations they had been in. They also valued when teachers answered their questions and discussed different diagnoses. Students were thankful for hints and suggestions from supervisors, especially those which were based on their work experiences.

Students valued the possibility of learning new things - new tests, new therapeutic skills and methods, new technical advices, something they had not learned in school. They learned new motivational skills and how to plan realistically. Some students mentioned that they learned to work with children and their parents.

\section{Giving feedback}

Students were thankful for getting constructive feedback about their weaknesses and correcting their mistakes. Analyses after doing practical exercises were appreciated.

\section{Negative remarks}

At the same time, there were students who would have liked to have had more supervision during therapies. Several students reported that there was not enough feedback or the feedback was not well given, not offering enough information for improvement of the work. Students expressed feeling that they did not get enough answers to their questions nor help when they needed it. They reported a lack of explanations and teaching when using different methods and doing therapies.

\section{Context and content of the practical training}

In addition to the comments about supervisors, students described what was helpful or not helpful for them in the placement setting and the content of the practical training. Students were content with their training when they saw different patients who had varied diagnoses. They also liked when the 
placement was a well-equipped and the emotional climate was friendly and positive. Some of them observed smooth interdisciplinary cooperation and cooperation of supervisors.

However, some of the environments were not as well-equipped. Sometimes therapy halls were too small or crowded, there was lack of crucial technical tools or there were not enough therapists. Sometimes there were not enough patients, or the supervisor did let students work with all patients. In bigger group lessons, students did not learn enough because they were not assessed adequately.

Sometimes students had feelings that they did not do anything educative. Some mentioned that most of their time was spent in helping children to dress. Others desired more observation opportunities or more explanations. Sometimes students felt that the emotional climate was tense or they did not understand the rules. Additionally, one student reported that there was really not interdisciplinary teamwork and when they tried to initiate it, this was not accepted.

\section{DISCUSSION}

When evaluating the results of the empirical research, it is important to remember that these are just opinions and impressions of students, who might not always see the bigger picture. However, the fact that they mentioned similar things from the positive and negative point of view shows that these aspects were important for their learning at the practical training.

Feedback to the experience of practical training shows that students appreciate highly this unique experience and value the role of supervisor. There are several aspects mentioned. Compared to the two elements of positive learning climate mentioned above, students in the current research valued acceptance, availability and support from the supervisors. They did not mention enthusiasm and genuine interest, but some other hints like asking questions, giving homework or giving meaningful tasks may be signs of that. Research confirms the claim by Cotrell et al. [3] that the effectiveness of the clinical training depends more on supervisory relationship and less on supervisory methods used. Even though it is hard to say exactly where one starts and another ends.

Students mentioned that their self-confidence grew during the practical training. This might be the sign of proceeding through the classical stages of practical training. In this research respondents observed questions, advice and feedback as the ways that supervisors improved their professional competence. 
Interestingly, students of this research do not mention the role of fellow students. The reason is that they mostly do their practical exercise alone, are supervised alone and therefore there are no fellow students to rely on. Hence, this increases, even more, the importance of the relationship between the student and working professional - supervisor.

Although students do not have enough experience to evaluate if the practical training serves more the interests of patients or students, there were indications which referred to the need of finding proper balance between these two sides. In an effort to learn more about that, there is a need for follow-up research focused on practical training. Meanwhile, the results of the current article could be used in the training of supervisors or in the case of writing guidelines about how to plan and lead the supervisory process.

In conclusion, the possibility to gain knowledge and skills from the practical training is a unique experience for students. Thus, being in practical training does not always mean that these possibilities become learning situations. There are several challenges facing different parties involved. The basic element is good relationship between the student and supervisor. Students' expectations are to be active participants in decision making and the clinical education process. Therefore, it is important to value both parties for their different skills and knowledge that can be shared under conditions of mutual respect and increase awareness of collaboration possibilities that benefit all participants.

\section{ACKNOWLEDGEMENT}

We are extremely grateful to the study participants who shared their experiences with us.

\section{REFERENCES}

1. Baldry Currens J. (2003) The 2:1 Clinical Placement Model. Physiotherapy, 89: 540-554

2. Corey G, Corey M, Callanan P. (2003) Issues and Ethics in the Helping Professions (6th ed) Pacific Grove, CA: Brooks/Cole

3. Cotrell D, Kilminster S, Jolly B, Grant J. (2002) What is Effective Supervision and How does it Happen? A Critical Incident Study. Med Educ, 36: 1042-1049

4. Diambra JF, Cole-Zakrzewski KG, Booher JA. (2004) Comparison of Internship Stage Models: Evidence from Intern Experiences. J Exp Educ, 27: 191-212

5. Donaghy ME, Morss K. (2000) Guided Reflection: A Framework to Facilitate and Assess Reflective Practice within the Discipline of Physiotherapy. Physioth Theory Pract, 16: 3-14 
6. Ernstzen DV, Bitzer E, Grimmer-Somers K. (2009) Physiotherapy Students ` and Clinical Teachers ` Perceptions of Clinical Learning Opportunities: A Case Study. Med Teach, 31: 102-115

7. Gwyer J, Odom C, Gandy J. (2003) History of Clinical Education in Physical Therapy in the United States. J Phys Ther Educ, 17: 34-43

8. Kell C, Jones L. (2007) Mapping Placement Educators`Conceptions of Learning. Physiotherapy, 94: 273-282

9. Kilminster S, Cotrell D, Grant J, Jolly B. (2007) AMEE Guide No 27: Effective Educational and Clinical Supervision. Med Teach, 29: 2-19

10. Kilminster S, Jolly B, Van Der Vleuten CPM. (2002) A Framework for Effective Training for Supervisors. Med Educ, 24: 385-389

11. Ladyshewski RK. (2004) Impact of Peer-Coaching on the Clinical Reasoning of the Novice Practitioner. Physiotherapy Canada 56: 15-25

12. Lindquist I, Engardt M, Garnham L, Poland F, Richardson B. (2006) Development Pathways in Learning to be Physiotherapist. Physioth Res Int, 11: 129-139

13. Skøien AK, Vagstøl U, Raaheim A. (2009) Learning Physiotherapy in Clinical Practice: Student Interaction in a Professional Context. Physioth Theory Pract, 25: $268-278$

14. Spouse J. (2001) Bridging Theory and Practice int he Supervisory Relationship: a Sociocultural Perspective. J Adv Nurs, 33: 512-522

15. Sweitzer HF, King MA. (1994) Stages of an Internship: an Organising framework. Hum Serv Educ, 14: 25-38

16. Vagstøl U, Skøien AK. (2011) A Learning Climate for Discovery and Awareness: Physiotherapy Students ' Perceptions on Learning and Supervision in Practice. Adv Physioth, 13: 71-78

\section{Correspondence to:}

Kadri Pill

Institute of Exercise Biology and Physiotherapy

University of Tartu

Ravila 14a, 50411, Tartu, Estonia

E-mail: kadri.pill@ut.ee 